Article

\title{
Single-Switch Bipolar Output DC-DC Converter for Photovoltaic Application
}

\author{
Salvador P. Litrán ${ }^{1, *(\mathbb{C}}$, Eladio Durán ${ }^{2} \mathbb{D}$, Jorge Semião ${ }^{3}$ and Rafael S. Barroso ${ }^{1}$ \\ 1 Department of Electrical and Thermal Engineering, Design and Projects, University of Huelva, \\ 21001 Huelva, Spain; rafael.barroso@die.uhu.es \\ 2 Department of Electronic Engineering, Computer Systems and Automation, University of Huelva, \\ 21001 Huelva, Spain; aranda@uhu.es \\ 3 ISE, Universidade do Algarve, 8005-139 Faro, Portugal/INESC-ID, 1000 Lisboa, Portugal; jsemiao@ualg.pt \\ * Correspondence: salvador@uhu.es; Tel.: +34-959217585
}

Received: 23 June 2020; Accepted: 16 July 2020; Published: 18 July 2020

check for updates

\begin{abstract}
Bipolar DC grids have become an adequate solution for high-power microgrids. This is mainly due to the fact that this configuration has a greater power transmission capacity. In bipolar DC grids, any distributed generation system can be connected through DC-DC converters, which must have a monopolar input and a bipolar output. In this paper, a DC-DC converter based on the combination of single-ended primary-inductor converter (SEPIC) and Ćuk converters is proposed, to connect a photovoltaic (PV) system to a bipolar DC grid. This topology has, as main advantages, a reduced number of components and a high efficiency. Furthermore, it can contribute to regulate/balance voltage in bipolar DC grids. To control the proposed converter, any of the techniques described in the literature and applied to converters of a single input and single output can be used. An experimental prototype of a DC-DC converter with bipolar output based on the combination of SEPIC and Ćuk converters was developed. On the other hand, a perturb and observe method ( $P$ and $\mathrm{O}$ ) has been applied to control the converter and has allowed maximum power point tracking (MPPT). The combined converter was connected in island mode and in parallel with a bipolar DC microgrid. The obtained results have allowed to verify the behavior of the combined converter with the applied strategy.
\end{abstract}

Keywords: bipolar DC microgrid; DC-DC converter; photovoltaic energy

\section{Introduction}

Nowadays, the use of renewable energies is a reality. According to recent articles of economic/business analysis and electric/electronic industry publications, in many countries, this type of energy represents a high percentage of the energy consumed. Nevertheless, international agreements against climate change suggest that the percentage of energy from renewable resources should increase in the coming years. Furthermore, it is necessary to increase the number of this type of facilities, and improve their efficiency [1,2]. A clear example is the imminent electrification and expansion of the transport sector that makes necessary direct links between renewable energy and electric vehicles (EVs), in grid power.

Within the renewable energies, photovoltaic (PV) energy is one of the most installed. To increase the installed power of this technology, it has been proposed to use more efficient technologies, and reduce the facilities' cost [3,4]. Technological advances in solar power include the increased efficiency [5], the reduction of overheads, reduced size of films, use of polymers, utilization of new materials for solar power cells, improvements of DC-AC converters for connection to the grid [6-9] and new architectures for power management. 
There are several possible configurations for PV systems: (i) centralized configuration, where the PV panel can be connected together, and DC power is delivered to one converter; (ii) string configuration, when several PV panels are connected in rows, and each row has its own converter; and (iii) modular configuration, where each PV module is connected to one converter.

The most common PV plant topology consists of a specific module of PV panels connected in series, forming a string or array. The connection of several strings in parallel will configure the corresponding solar plant. There are several configurations for PV systems if we consider the DC bus connection [10]. A monopolar DC configuration uses a single wire; the return conductor may be land or metallic. Its main advantage is the use of a single cable. The PV plant is connected to a monopolar DC network through a DC-DC converter (Figure 1). The converter will adapt the voltage level between the DC bus and the PV modules, so that maximum power is transferred to the system with the adequate control strategy. The energy injected to the DC bus can be transferred to the utility through a DC-AC converter. A different topology for the DC bus is the bipolar DC configuration [11]. It consists of two wires, one with positive polarity and other with negative polarity. In normal operation, the current through ground is zero. It has two voltage levels, allowing, under fault conditions, a monopolar operation. The main advantage of the installation of a bipolar DC bus is the reduction in losses, which makes it possible to reduce the section of the wires, and therefore reduce the conductor volume or increase the transmission capacity. Finally, the DC bus can use a homopolar DC configuration. It has two or more wires with the same polarity, usually negative. The return may be by land or metallic. Its main advantage is the reduction in the costs of insulation; however, the return current is double.

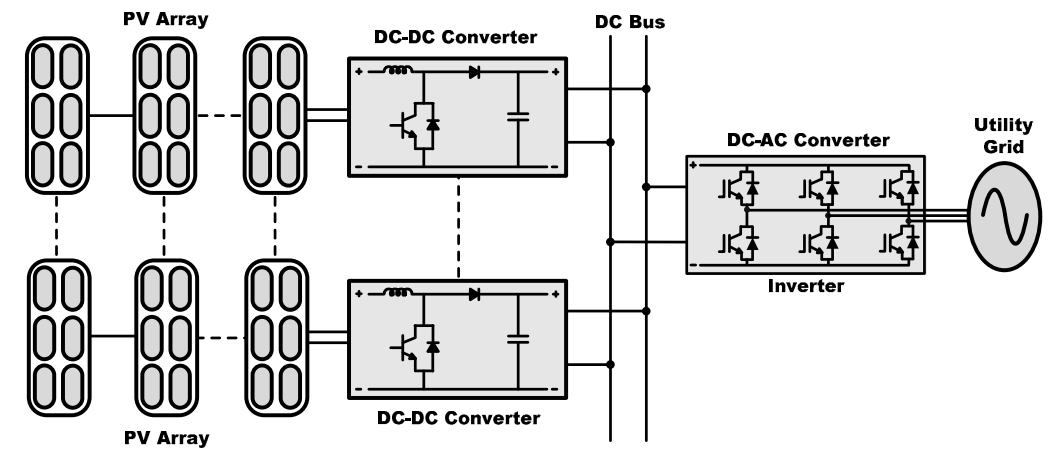

Figure 1. Centralized configuration with monopolar DC bus.

This work proposes the use of a bipolar DC bus instead of the monopolar DC bus, for which a new DC-DC converter topology is proposed, which allows the connection of each photovoltaic string to this bus $[12,13]$.

The connection of a distributed generation system with DC output to a bipolar network can be done in different ways. One of them is to include a DC-DC converter of one input and one bipolar output. When the appropriate control strategy is applied, this option allows setting the generator working point. Regarding the converters, different configurations have been proposed, both in isolated and non-isolated versions. Non-isolated versions are usually more advantageous than isolated versions, from the point of view of the efficiency, cost, volume and weight. The proposed DC-DC converter with one input and two outputs is based on the combination of two converters of one input and one output, such as the single-ended primary-inductor converter (SEPIC) and Ćuk [14-17]. It is a step-down/step-up converter. This topology is effective for this type of application, with high efficiency and with the use of only one controlled power switch. In addition, for the control of the maximum power point, any proposed technique for one input and one output converter can be used [18-24].

The combined SEPIC-Ćuk converter has been theoretically analyzed in $[14,15]$. However, in this paper, a design procedure is established for the use of these converters in the connection of photovoltaic systems to bipolar DC networks. The operation of the converter is analyzed for a system isolated 
and connected to the network. On the other hand, a control strategy has been applied so that the photovoltaic system works at its maximum power point.

In this paper, a comparison between bipolar DC and monopolar DC grids is included in Section 2. In Section 3, the combined converter SEPIC-Ćuk topology is described. In Section 4, an experimental prototype is designed, and a control strategy applied so that the set operates at the point of maximum power transfer. Experimental results are also presented. Finally, Section 5 presents the conclusions of this work.

\section{Monopolar Versus Bipolar DC Grid}

A monopolar DC grid consists of two wires between which a DC voltage is defined. Any load can be connected to this network at the voltage $V_{d c}$ (Figure 2a).

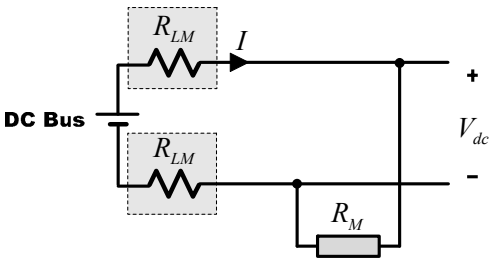

(a)

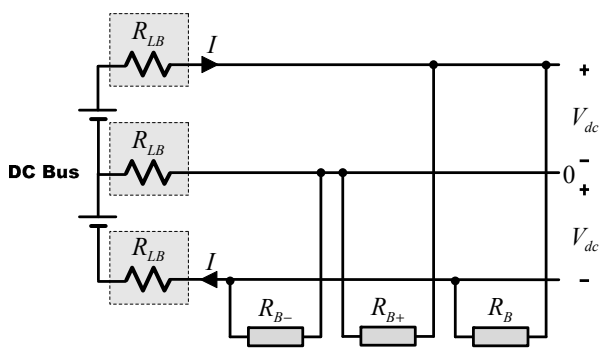

(b)

Figure 2. (a) Monopolar DC grid; (b) bipolar DC grid.

On the other hand, the bipolar DC grid (Figure 2b) is formed by three wires, " +", "-" and " 0 ". Each load can be connected to two different voltage levels: $V_{d c}$ if the load is connected between " + " and " 0 " or between " 0 " and " - ", and $2 V_{d c}$ if the load is connected between " + " and "-". Another characteristic to highlight is when the loads connected between " + " and " 0 " and between "-" and " 0 " are balanced, the current through the wire " 0 " is null; therefore, if this criterion is taken in consideration when the loads are connected, the section of this " 0 " wire can be significantly reduced.

In Figure $2 \mathrm{a}, R_{L M}$ represents the resistance of the wires for a monopolar DC grid. In Figure $2 \mathrm{~b}$, $R_{L B}$ represents the wire resistances for the bipolar DC grid.

When the two topologies are compared, for the same power transmission conditions in both grids and wires of the same section, the power losses in the bipolar DC grid are a quarter of the losses that occur in the monopolar DC grid.

The comparison of the two topologies with the same losses and wires of the same section results that the bipolar DC grid can transmit twice as much power as in the monopolar DC grid.

Finally, when the power losses and the transmission power in both are equal, the relationship between line resistances in both topologies can be calculated. Therefore, the resistance of the bipolar DC grid is four times greater than the resistance of the monopolar DC grid. This means that the wire section in the bipolar grid is a quarter of the monopolar grid.

Therefore, from the point of view of the power losses, the transmission power and the section of the wires, bipolar DC grids have advantages with respect to monopolar DC grids, which are usually used.

\section{Proposed Converter}

The connection of a distributed generation system with DC output to a bipolar network can be done in different ways. One of them is to include a DC-DC converter of one input and one bipolar output. When the appropriate control strategy is applied, this option allows setting the generator working point. For the connection of a PV system to a bipolar grid, different solutions based on DC-DC converters have been analyzed [8,9]. Regarding the converters, different configurations have been proposed, both in isolated and non-isolated versions. Non-isolated versions are usually more 
advantageous than isolated versions, from the point of view of the efficiency, cost, volume and weight. In this sense, various configurations with bipolar output have been proposed in the literature, all of them have in common the use several power switches and several reactive components. In [11,25], a three-level boost converter was reported, to provide two bipolar output voltages. It required an inductor, two switches (one of them floating) and two diodes. In [26], a three-level boost converter with two inductors was shown. It provided two bipolar output voltages also. Three-level boost converters are widely used in low-voltage bipolar-type DC microgrids. In the same way, a three-level DC-DC converter with coupled inductors for high-power applications was proposed in [27]. A single-inductor power converter with buck-boost capability, two switches (one of them floating) and three diodes was presented in [28], where the switches operated in overlapping mode. A bipolar output DC-DC converter was proposed in [29], consisting of two basic DC-DC converters. The first one was a boost converter and the second was a DC-DC buck-boost converter. Both operated in a complementary way, in a series-combined boost and buck-boost converter. A dual-output DC-DC boost converter was reported in [30], where it employed two inductors, two diodes and two switches.

In this work, a converter based on the combination of SEPIC and Ćuk converters is proposed. Figure 3 shows the configuration of this converter. This combination is based on the fact that both converters have the same input, one power switch and one input inductor. They have the same conversion ratio and the output of the Ćuk converter is inverted with respect to that of the SEPIC. Therefore, its combination allows obtaining a bipolar output voltage from a monopolar input.

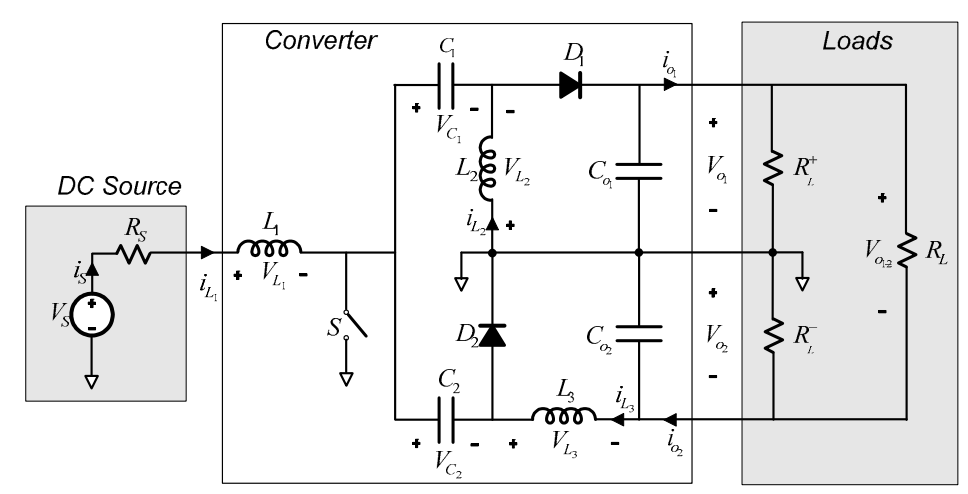

Figure 3. SEPIC (single-ended primary-inductor converter)-Ćuk combination converter.

This configuration employs only one power switch, three inductors, two link capacitors and two diodes. It has an advantage over the other proposals in that it has a reduced number of components. Only one power switch is necessary, which has its gate referenced to ground what simplifies the design of the gate drivers. This makes both the power switch and the input inductor concentrate all the input current, and it is also possible to couple several power switches and several inductors in parallel to distribute the current, allowing a synchronous or overlapping mode (the same control signal) or interleaved mode (shifting phase the control signals of each switch).

The converter can work in two operating modes: continuous conduction mode (CCM) and discontinuous conduction mode (DCM). CCM means that the inductor current is continuous. On the other hand, in DCM, the current of the inductor is discontinuous, i.e., in a time interval of the switching period, this current is zero.

The operation of the converter, in steady state, can be analyzed through a simple model with controlled sources. Figure 4 shows the equivalent circuit. $R_{s}$ and $V_{s}$ represent the equivalent of the DC source. The relationship between input and output variables can be expressed as

$$
\left[\begin{array}{c}
I_{g} \\
V_{o}^{+} \\
V_{o}^{-}
\end{array}\right]=\left[\begin{array}{lll}
k & k & 0 \\
0 & 0 & k \\
0 & 0 & k
\end{array}\right]\left[\begin{array}{c}
I_{o}^{+} \\
I_{o}^{-} \\
V_{g}
\end{array}\right]
$$


where the parameter $k$ depends on the operating mode of the converter. If the converter works in CCM, $k$ must be

$$
k=\frac{D}{1-D}
$$

where $D$ is the duty cycle.

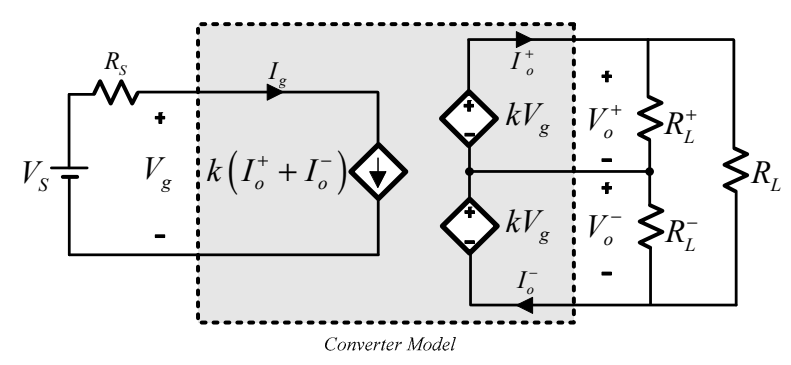

Figure 4. Converter model with controlled sources.

In the case of DCM, the value of $k$ is given by the expression

$$
k=D \sqrt{\frac{R_{o} T_{S}}{2 L_{e q}}}
$$

Here, $T_{S}$ is the switching period and according to Figure $3, R_{o}$ and $L_{e q}$ are given by

$$
\begin{gathered}
\frac{1}{R_{o}}=\frac{1}{R_{L}^{+}}+\frac{1}{R_{L}^{-}}+\frac{4}{R_{L}} \\
\frac{1}{L_{\text {eq }}}=\frac{1}{L_{1}}+\frac{1}{L_{2}}+\frac{1}{L_{3}}
\end{gathered}
$$

In PV applications, the converter works by following the maximum power point of the source. For this, the following condition must be fulfilled:

$$
R_{S}=R_{g}
$$

Here, $R_{g}$ is the equivalent resistance from the terminal of the controlled current source.

A PV system in isolated operation can be represented by the circuit shown in Figure 4. At the input loop, the current is given by

$$
I_{g}=k\left(I_{o}^{+}+I_{o}^{-}\right)=k\left[\frac{V_{o}^{+}}{R_{L}^{+}}+\frac{V_{o}^{-}}{R_{L}^{-}}+\frac{2\left(V_{o}^{+}+V_{o}^{-}\right)}{R_{L}}\right]
$$

That can be expressed in the way of

$$
I_{g}=k^{2} V_{g}\left(\frac{1}{R_{L}^{+}}+\frac{1}{R_{L}^{-}}+\frac{4}{R_{L}}\right)
$$

Therefore, according Equation (6), it must fulfill

$$
R_{S}=\frac{R_{o}}{k^{2}}
$$

Equation (9) is useful when the system is operating in isolated mode, since it allows to determine the duty cycle under different load conditions when the system is transferring the maximum power. 
In many applications, the PV system is connected to a bipolar grid in parallel with other sources. When the same model of controlled sources is considered, the equivalent circuit from the bipolar network is useful because it allows the analysis of the power flows and establishing the range of powers when the converter works in CCM mode. In this case, from the terminals of the bipolar grid, the equivalent circuit of the converter can be obtained. Figure 5 shows the equivalent voltage, which is $k V_{S}$, and the value equivalent resistance, $2 k^{2} R_{S}$.

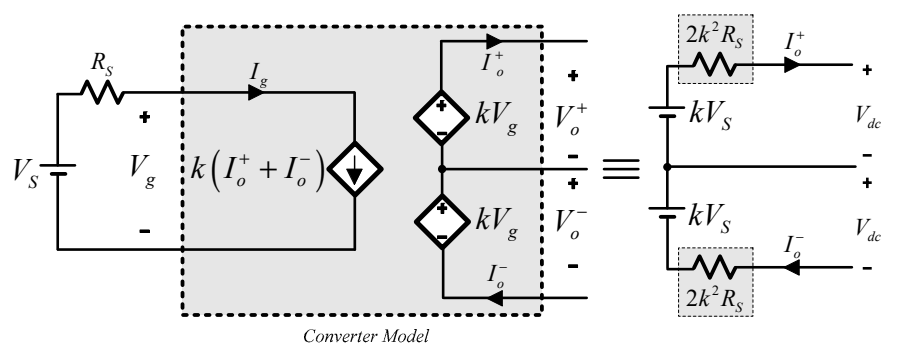

Figure 5. Converter model from output terminals.

Under the conditions of maximum power

$$
\begin{aligned}
V_{S} & =2 V_{g} \\
P & =\frac{V_{g}^{2}}{R_{S}}
\end{aligned}
$$

where $V_{g}$ is the output voltage of the PV system when the maximum power $P$ is transferred.

For a balanced bipolar grid of voltage $\pm V_{d c}$, at the positive output, transferred power can be expressed by

$$
P^{+}=\frac{P}{2}=\frac{V_{g}^{2}}{2 R_{S}}=V_{d c} I_{o}^{+}
$$

So, from the equivalent circuit in Figure 5, the next equation can be established as

$$
\frac{2 k V_{g}-V_{d c}}{2 k^{2} R_{S}}=I_{o}^{+}
$$

When $I_{0}{ }^{+}$is substituted in Equation (12) from Equation (11)

$$
\frac{2 k V_{g}-V_{d c}}{2 k^{2} R_{S}}=\frac{V_{g}^{2}}{2 R_{S} V_{d c}}
$$

Obtaining $k$ from Equation (13) and taking into account that the system must supply power, it is deduced

$$
k=\frac{V_{d c}}{V_{g}}
$$

Therefore, $k$ only depends on the voltage at the connection point of the converter and the output voltage of the photovoltaic system at the maximum power point (MPP).

Equation (14) allows to obtain the duty cycle of the converter for different conditions of grid voltage and input voltage at the MPP.

From the point of view of the converter component design, Table 1 shows the average values of voltages and currents for each of the converter elements when it works in steady state. It is assumed that the converter operates in CCM. This mode of operation is the preferred in power systems due to its higher efficiency, so this operation mode is the most adequate for the proposed application. It should be noted that the voltage at the $C_{2}$ capacitor (Ćuk side) is higher than the voltage at the $C_{1}$ capacitor (SEPIC side). Choosing the appropriate values for the inductors and capacitors is of special importance for the proper operation of the converter. 
Table 1. Performance of the combination of SEPIC (single-ended primary-inductor converter) and Ćuk converters.

\begin{tabular}{cccc}
\hline & Switch & $D_{1}$ & $D_{2}$ \\
\hline Semiconductor Voltages & $V_{g}+V_{o}^{+}$ & $V_{g}+V_{o}^{+}$ & $V_{g}+V_{o}^{-}$ \\
Semiconductor Average Currents & $\frac{V_{g} D^{2}}{R_{o} \cdot(1-D)^{2}}$ & $\frac{V_{g} D}{R_{o}^{+} \cdot(1-D)}$ & $\frac{V_{g} D}{R_{o}^{-} \cdot(1-D)}$ \\
\hline- & $C_{1}$ & $C_{2}$ & - \\
\hline Capacitor Average Voltages & $V_{g}$ & $V_{g}+V_{o}^{-}$ & $L_{3}$ \\
\hline Inductor Average Currents & $\frac{L_{1}}{R_{g} \cdot(1-D)^{2}}$ & $\frac{V_{g} D}{R_{o}^{+} \cdot(1-D)}$ & $\frac{V_{g} D}{R_{o}^{-} \cdot(1-D)}$ \\
\hline Where: $\frac{1}{R_{o}}=\frac{1}{R_{L}^{+}}+\frac{1}{R_{L}^{-}}+\frac{4}{R_{L}} ;$ & $\frac{1}{R_{o}^{+}}=\frac{1}{R_{L}^{+}}+\frac{2}{R_{L}} ;$ & $\frac{1}{R_{o}^{-}}=\frac{1}{R_{L}^{-}}+\frac{2}{R_{L}}$ & \\
\hline
\end{tabular}

The selection of the $L_{1}$ inductor depends on the desired ripple value of the input current. Its peak-to-peak value is given by

$$
\Delta i_{L_{1}}=\frac{V_{g}}{L_{1}} D T_{S}
$$

$\Delta i_{L 1}$ is a percentage of the input current average.

For the choice of the $L_{2}$ and $L_{3}$ inductors, it is assumed that the converter works in CCM in a power range.

$$
I_{L 1}=\frac{V_{g} D^{2}}{R_{o} \cdot(1-D)^{2}}
$$

On the other hand, the combination of SEPIC and Ćuk converters works in CCM when the next expressions are fulfilled as

$$
\frac{2 L_{e q}}{R_{o} T_{S}}>(1-D)^{2}
$$

where $L_{e q}$ and $R_{o}$ are defined according Equation (5).

The selection of the link capacitors $C_{1}$ and $C_{2}$, for the SEPIC and Ćuk sides, is based on assuming that the voltage in those capacitors must be constant. The resonant frequencies $\left(\omega_{r}\right)$ must be lower than the switching frequency $\left(\omega_{S}\right)$, in order to ensure constant voltage.

To ensure that the converter operation mode is neither discontinuous quasi-resonant mode (DQRM) nor discontinuous capacitor voltage mode (DCVM), the resonant frequency must be

$$
\begin{gathered}
\omega_{S}>\omega_{r} ; \text { with } \omega_{r_{1}}^{2}=\frac{1}{C_{1}\left(L_{1}+L_{2}\right)} \text { for SEPIC side, } \\
\qquad \omega_{r_{2}}^{2}=\frac{1}{C_{2}\left(L_{1}+L_{3}\right)} \text { for Ćuk side } \\
\text { furthermore }: C_{1}>\frac{D^{2} T_{S}}{2 R_{o}} \text { and } C_{2}>\frac{D^{2} T_{S}}{2 R_{o}}
\end{gathered}
$$

In the same way, the voltage ripple in $C_{1}$ and $C_{2}$ is given by

$$
\begin{gathered}
\Delta v_{C_{1}}=\frac{V_{g} \cdot D^{2}}{(1-D) \cdot R_{0} \cdot C_{1} \cdot f_{S}} \Rightarrow \frac{\Delta v_{C_{1}}}{V_{o 1}}=\frac{D}{R_{o} \cdot C_{1} \cdot f_{S}}, \text { SEPIC } \\
\Delta v_{C_{2}}=\frac{V_{g} \cdot D^{2}}{(1-D) \cdot R_{0} \cdot C_{2} \cdot f_{S}} \Rightarrow \frac{\Delta v_{C_{2}}}{V_{o 2}}=\frac{D}{R_{o} \cdot C_{2} \cdot f_{S}}, \text { Cuk }
\end{gathered}
$$


The selection of the output capacitors $C_{01}$ and $C_{02}$ is also made to obtain the desired voltage ripple value. Its peak-to-peak value is given by

$$
\begin{aligned}
& \frac{\Delta v_{01}}{V_{o 1}}=\frac{D}{R_{o}^{+} \cdot C \cdot f_{S}}, \text { for SEPIC side } \\
& \frac{\Delta v_{02}}{V_{o 2}}=\frac{(1-D)}{8 \cdot L_{2} \cdot C \cdot f_{S}{ }^{2}}, \text { for Ćuk side }
\end{aligned}
$$

\section{Experimental Prototype}

An experimental prototype of the proposed DC-DC converter has been designed, based on the circuit shown in Figure 3. The prototype is a scaled model that allows the verification of its operation in the laboratory. Figure 6 shows the experimental prototype.

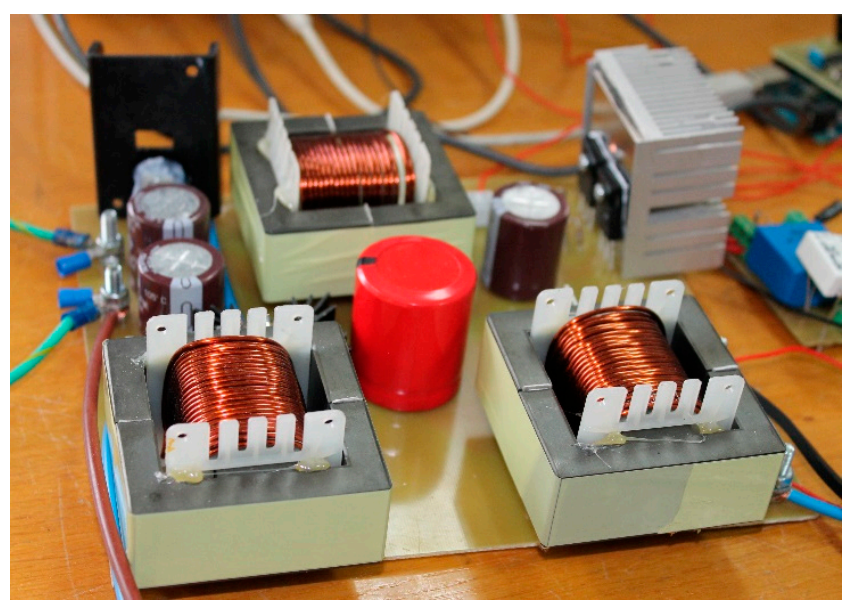

Figure 6. Experimental prototype.

The designed converter allows the connection of a PV system to a bipolar DC microgrid of $\pm 100 \mathrm{~V}$. In this design, an array consisting of three monocrystalline photovoltaic modules from Isofoton, model ISF-250, have been considered. Table 2 shows its performance at an irradiance of $1000 \mathrm{~W} / \mathrm{m}^{2}$ and cell temperature of $25^{\circ} \mathrm{C}$.

Table 2. ISF-250 model. Performance at an irradiance of $1000 \mathrm{~W} / \mathrm{m}^{2}$ and cell temperature of $25{ }^{\circ} \mathrm{C}$.

\begin{tabular}{cc}
\hline Rated Power $\left(P_{\max }\right)$ & $250 \mathrm{~W}$ \\
Open Circuit Voltage $\left(V_{o c}\right)$ & $37.8 \mathrm{~V}$ \\
Short-Circuit Current $\left(I_{s c}\right)$ & $8.75 \mathrm{~A}$ \\
Maximum Power Point Voltage $\left(V_{\max }\right)$ & $30.6 \mathrm{~V}$ \\
Maximum Power Point Current $\left(I_{\max }\right)$ & $8.17 \mathrm{~A}$ \\
Efficiency & $15.1 \%$ \\
\hline
\end{tabular}

For this string, the open circuit voltage is $114 \mathrm{~V}$ and short-circuit current is $8.75 \mathrm{~A}$.

In the maximum power conditions, the voltage varies from 85 to $92.5 \mathrm{~V}$, depending on the irradiance, for a temperature of $25^{\circ} \mathrm{C}$. On the other hand, when the irradiance is $1000 \mathrm{~W} / \mathrm{m}^{2}$, the voltage varies from 75 to $98 \mathrm{~V}$, according to the temperature. Figure 7 shows the variation in the output voltage for different irradiances and different temperatures.

With respect to the power, it varies from $72\left(100 \mathrm{~W} / \mathrm{m}^{2}, 25^{\circ} \mathrm{C}\right)$ to $796 \mathrm{~W}\left(1000 \mathrm{~W} / \mathrm{m}^{2}, 10^{\circ} \mathrm{C}\right)$, which will be taken as design values to the converter. 

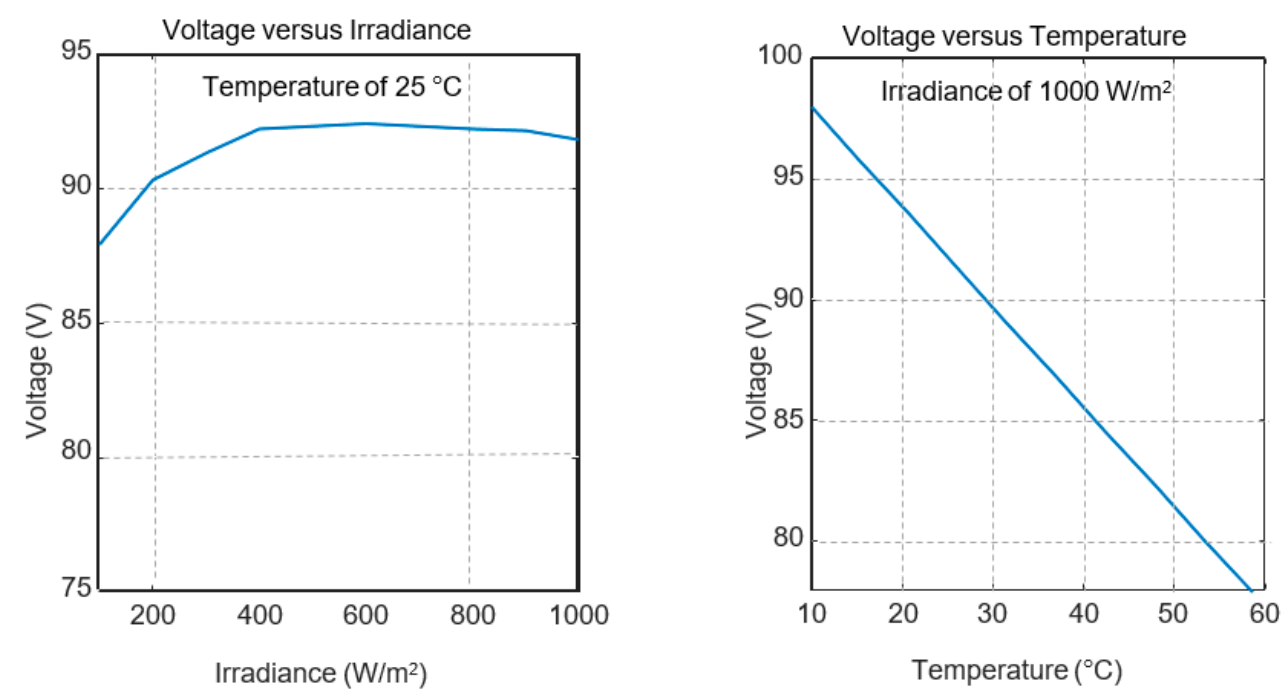

Figure 7. Characteristic curves for maximum power of photovoltaic string of 3 series modules of Isofoton ISF-250.

\subsection{Converter Design}

The selection of the components of the SEPIC-Ćuk combined converter shown in Figure 3 is stablished according the peak power of the string where the converter will be connected. Therefore, the prototype will be designed for a power of $1 \mathrm{~kW}(0.25 \mathrm{~kW}$ above maximal power). The voltage at maximum power for different irradiance can vary from 75 to $98 \mathrm{~V}$. Thus, according to Equation (14), the duty cycle of the converter will be between 0.51 and 0.57 . The switching period is established at $40 \mu$ s. Table 3 shows the main design features of the converter.

Table 3. Main features of the converter.

\begin{tabular}{cc}
\hline Rated Power & $1000 \mathrm{~W}$ \\
Maximum Input Current & $8.2 \mathrm{~A}$ \\
Range of Input Voltages & $88-98 \mathrm{~V}$ \\
Rated Output Voltage & $100 \mathrm{~V}$ \\
Switching Frequency & $25 \mathrm{kHz}$ \\
\hline
\end{tabular}

The maximum input current is given for the maximum power, it is $8.17 \mathrm{~A}$. On the other hand, the maximum ripple of the input current is set to $4 \%$. The application of Equation (15) results in an inductance, $L_{1}$, of $5 \mathrm{mH}$.

For the lower power, $72 \mathrm{~W}$, the input voltage is $88 \mathrm{~V}\left(100 \mathrm{~W} / \mathrm{m}^{2}, 25^{\circ} \mathrm{C}\right)$, and the maximum load $R_{o}$ can be calculated, which results in $R_{0}=103 \Omega$.

If $R_{o}{ }^{+}=R_{o}{ }^{-}=R_{o}=103 \Omega$, according to Equation (17), the inductance $L_{e q}$ must be greater than $0.47 \mathrm{mH}$. Furthermore, considering $L_{2}=L_{3}$, its values will be of $1.03 \mathrm{mH}$. In this design, $L_{2}=L_{3}=$ $1 \mathrm{mH}$ was chosen.

For a switching period $\left(T_{S}\right)$ of $40 \mu$ s and $f_{S}=100 f_{r}$, the Equation (18) are satisfied for a minimum capacity value of $101 \mu \mathrm{F}$ (for $C_{1}$ and $C_{2}$ ). Therefore, a standard value of $470 \mu \mathrm{F}$ is chosen. With respect to the voltage ripple, the application of Equation (19) with $C_{1}=C_{2}=470 \mu \mathrm{F}$ allows to obtain a ripple of $0.4 \%$, when the load is maximum, which is when $D=0.52$ and $R_{o}=11.1 \Omega$.

Finally, for the selection of the output capacitors $C_{01}$ and $C_{02}$, Equation (20) is applied. For a low-voltage ripple, $C=470 \mu \mathrm{F}$ has been considered, which provides an estimated voltage ripple of $0.4 \%$ for $V_{o}^{+}$and $0.1 \%$ for $V_{o}^{-}$.

Table 4 summarizes the characteristics of the SEPIC-Ćuk combined converter components implemented. 
Table 4. DC-DC combined converter components.

\begin{tabular}{cc}
\hline$D_{1}, D_{2}$ & MUR1560, 600 V (ON Semiconductor, Denver, Colorado, USA), 15 A \\
$S$ & IGBT50N60T (Infineon Technologies AG, Munich, Germany) 600 V, \\
$L_{1}$ & $50 \mathrm{~A}$ \\
$L_{2}, L_{3}$ & $5.0 \mathrm{mH}, 20 \mathrm{~A}$ \\
$C_{1}$ & $1.0 \mathrm{mH}, 10 \mathrm{~A}$ \\
$C_{2}$ & $470 \mu \mathrm{F}, 250 \mathrm{~V}$ \\
$C$ & $470 \mu \mathrm{F}, 400 \mathrm{~V}$ \\
\hline
\end{tabular}

\subsection{Control Strategy}

For the control of the converter, several strategies can be applied to the proposals in the technical literature for converters of one input and one output [18-24]. In this work, the technique chosen allows maximum power point tracking. The perturb and observe method $(\mathrm{P}$ and $\mathrm{O})$ is one of the most used in practice [24]. It is an iterative method where the reference voltage varies according to the increase in power, obtained from the input voltage and current to the converter. Figure 8 shows the flowchart of the $\mathrm{P}$ and $\mathrm{O}$ strategy.

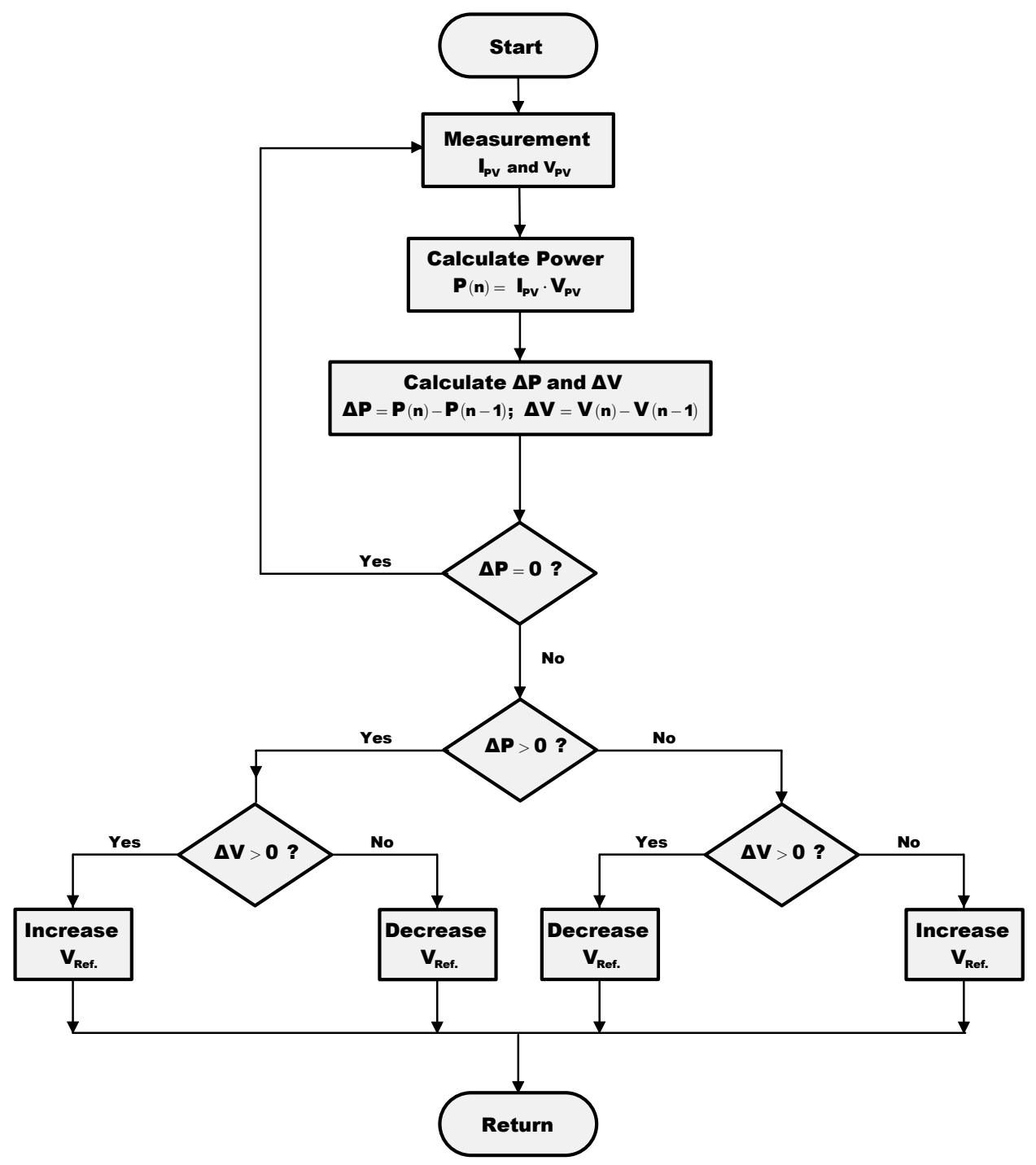

Figure 8. Perturb and observe method flowchart. 
The control strategy has been implemented in the TMS320F28335 Delfino Microcontroller by Texas Instruments Dallas, Texas, USA. The measuring sensors used are the LA 25-NP for the currents and the LV 25-1000 for the voltage, both by LEM International SA, Geneva, Switzerland.

\subsection{Experimental Results}

The experimental system set-up is shown in Figure 9. The DC-DC converter will connect to a bipolar DC microgrid of $\pm 100 \mathrm{~V}$. It has been designed for a maximum power of $5 \mathrm{~kW}$. In the test, three resistors have been connected. They have the following values: $R_{L}{ }^{+}=R_{L}{ }^{-}=47 / 2 \Omega$ and $R_{L}=47 \Omega$.

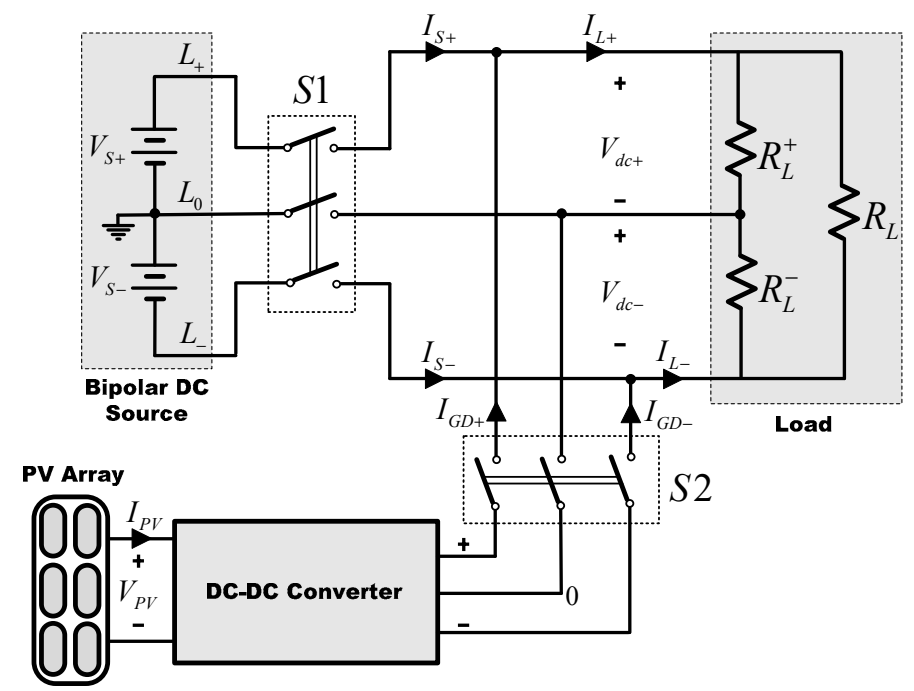

Figure 9. Experimental system.

When the switch $S 1$ is closed and $S 2$ is open, the $V_{d c+}$ and $V_{d c-}$ voltages have an average value of $100 \mathrm{~V}$. The current for each conductor is $I_{L}{ }^{+}=8.5 \mathrm{~A}$ and $I_{L}{ }^{-}=-8.5 \mathrm{~A}$, so that the power consumed by the set is $1.7 \mathrm{~kW}$.

The PV system is emulated by a DC source, so the point of maximum power can be adjusted to a desired value, modifying its internal resistance and voltage.

Figure 10 shows the curves $I-V$ and $P-V$ of a photovoltaic string of three series of modules of Isofoton ISF-250 for a given irradiance. In this situation, the maximum power is given for $750 \mathrm{~W}$ with a voltage of $91.8 \mathrm{~V}$ and a current of $8.2 \mathrm{~A}$.
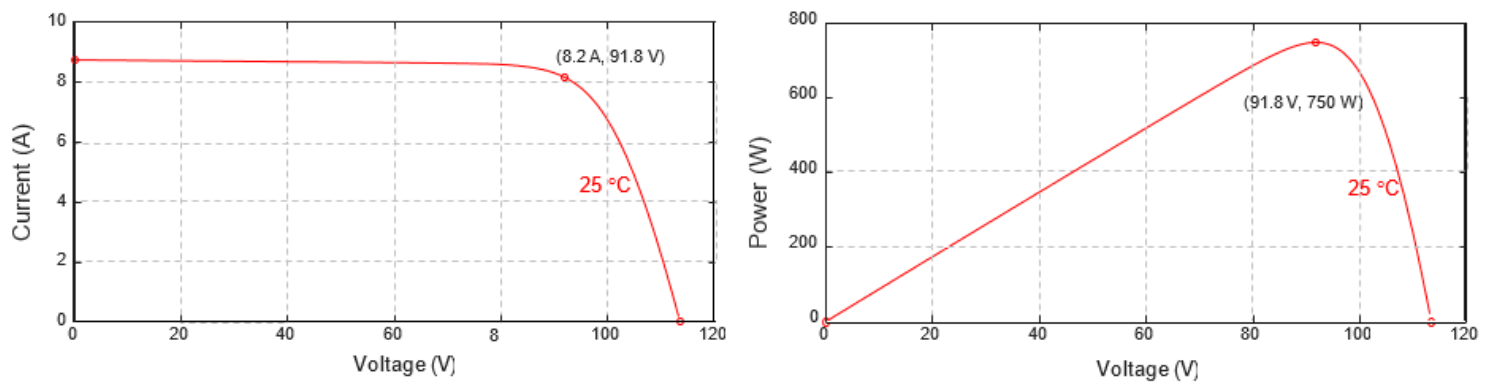

Figure 10. Curves $I-V$ and $P-V$ of one photovoltaic string of 3 series of modules of Isofoton ISF-250. Irradiance $1000 \mathrm{~W} / \mathrm{m}^{2}$

The DC source is adjusted to an output voltage of $182.4 \mathrm{~V}$, with an internal resistance $\left(R_{s}\right)$ of $11.1 \Omega$. Therefore, the DC source will transfer the maximum power $(750 \mathrm{~W})$ when it supplies a current of 8.17 A and with an output voltage of $91.8 \mathrm{~V}$. 
In the following test, the switch $S 1$ is open and the switch $S 2$ is closed. Thus, the PV system is operating in island mode. According with Equation (4), $R_{o}=5.9 \Omega$ for the resistance values $R_{L}{ }^{+}$, $R_{L}{ }^{-}$and $R_{L}$. Therefore, the application of Equation (9) let the obtaining of $k=0.73$, resulting in a theoretical duty cycle of $42 \%$. The measured power is $638 \mathrm{~W}$, the voltage $V_{d c+}=-V_{d c-}=62.5 \mathrm{~V}$ and the currents $I_{L+}=-I_{L-}=5.1 \mathrm{~A}$. With respect to the current $\left(I_{P V}\right)$ and voltage $\left(V_{P V}\right)$ at the input converter, their average values are $8.2 \mathrm{~A}$ and $92.1 \mathrm{~V}$, respectively. Thus, the efficiency is $84.4 \%$. Figure 11 shows the gate source signal, $V_{g}$, drain source voltage, $V_{d s}$, and the input current waveform. The measured duty cycle in these conditions is $41 \%$, similar to the theoretical value.

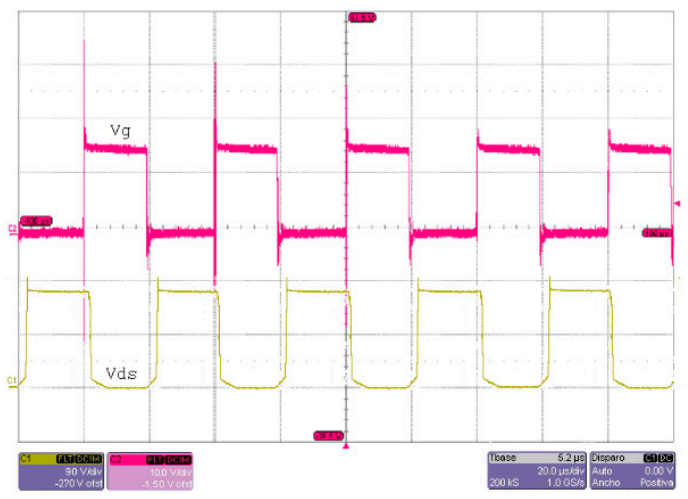

(a)

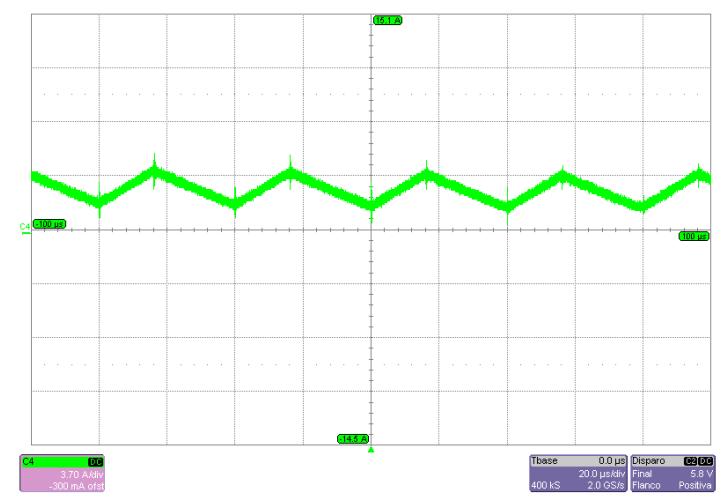

(b)

Figure 11. Gate source signal, $V_{g}$, and drain source voltage, $V_{d s}(\mathbf{a})$, and input current waveform (b) when the photovoltaic system operates in island mode.

When the PV system and source are connected (Figure 9, S1 and S2 are closed), the voltages at the point of connection are $V_{d c+}=-V_{d c-}=99.7 \mathrm{~V}$. From the theoretical point of view, Equation (14) must be fulfilled, therefore at the maximum power point, $k$ must be 1.09 and the theoretical duty cycle will be $52 \%$. The converter supplies a current $I_{G D+}=-I_{G D-}=3.2 \mathrm{~A}$, so the power transferred by the converter is $638 \mathrm{~W}$. The input voltage $\left(V_{P V}\right)$ is $92 \mathrm{~V}$ and the input current is $\left(I_{P V}\right) 8.1 \mathrm{~A}$. Figure 12 shows the gate source signal, $V_{g}$, drain source voltage, $V_{d s}$, and the input current waveform. In this case, the measured duty cycle is about $51 \%$. In this test, the measured efficiency of the converter is $86.5 \%$.

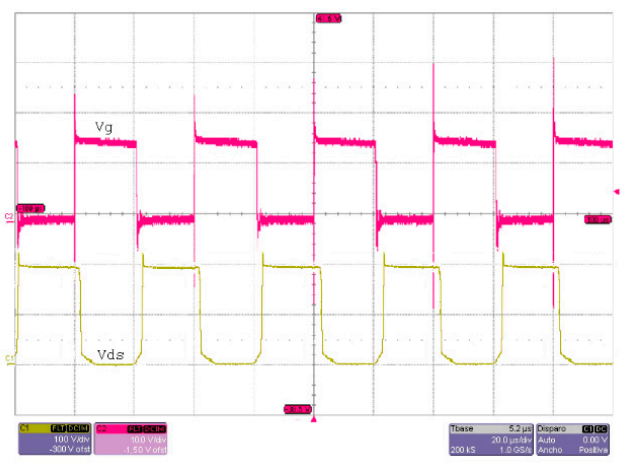

(a)

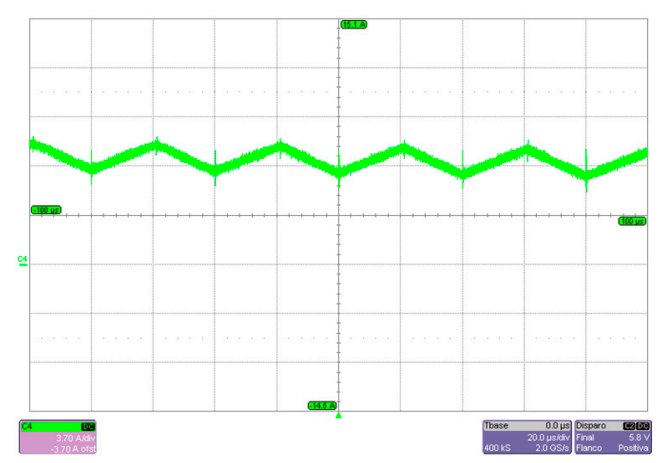

(b)

Figure 12. Gate source signal, $V_{g}$, and drain source voltage, $V_{d s}(\mathbf{a})$, and input current waveform (b) when the photovoltaic system operates in parallel with a bipolar DC source. 


\section{Conclusions}

Bipolar DC grids have become an adequate solution for high-power DC microgrids. When compared with monopolar DC grids, their main advantage lies in a greater power transmission capacity.

A distributed generation system can be connected to the bipolar DC microgrid through DC-DC converters. There are different converter configurations with bipolar output, however, all of them have several power switches. In this paper, a converter based on the combination of a SEPIC and a Ćuk converter is proposed. This topology has, as main advantages, a reduced number of components and the use of a single switch.

In the proposed converter control strategy, any of the techniques described in the literature applied to converters of a single output can be used. Among the different control strategies applied to PV systems, the most commonly used are those that allow maximum power point tracking.

In this paper, an experimental prototype DC-DC converter with bipolar output based on the combination of SEPIC and Ćuk converters was developed. This converter allows the connection of a PV system to a bipolar DC grid. In the control, the perturb and observe method has been applied which has allowed maximum power point tracking. The results obtained allowed to verify the behavior of the converter with the applied strategy.

Author Contributions: All of the Authors conceived and designed the experiments; performed the experiments; analyzed the data; contributed reagents/materials/analysis tools; wrote the paper. All authors have read and agreed to the published version of the manuscript.

Funding: This research received no external funding.

Conflicts of Interest: The authors declare no conflict of interest.

\section{References}

1. Chakraborty, C.; Iu, H.H.-C.; Lu, D.D.-C. Power converters, control, and energy management for distributed generation. IEEE Trans. Ind. Electron. 2015, 62, 4466-4470. [CrossRef]

2. Justo, J.J.; Mwasilu, F.; Lee, J.; Jung, J.W. AC-microgrids versus DC-microgrids with distributed energy resources: A review. Renew. Sustain. Energy Rev. 2013, 24, 387-405. [CrossRef]

3. El-Shahat, A.; Sumaiya, S. DC-Microgrid System Design, Control, and Analysis. Electronics 2019, 8, 124. [CrossRef]

4. Kamel, A.A.; Rezk, H.; Shehata, N.; Thomas, J. Energy management of a DC microgrid composed of photovoltaic/fuel cell/battery/supercapacitor systems. Batter 2019, 5, 63. [CrossRef]

5. Kurtz, S.; Repins, I.; Metzger, W.K.; Verlinden, P.J.; Huang, S.; Bowden, S.; Tappan, I.; Emery, K.; Kazmerski, L.L.; Levi, D. Historical Analysis of Champion Photovoltaic Module Efficiencies. IEEE J. Photovolt. 2018, 8, 363-372. [CrossRef]

6. Carrasco, J.M.; Franquelo, L.G.; Bialasiewicz, J.T.; Galvan, E.; Portillo, R.; Prats, M.A.M.; Leon, J.I.; Moreno-Alfonso, N. Power-electronic systems for the grid integration of renewable energy sources: A survey. IEEE Trans. Ind. Electron. 2006, 53, 1002-1016. [CrossRef]

7. Zapata, J.W.; Kouro, S.; Carrasco, G.; Meynard, T.A. Step-down partial power dc-dc converters for two-stage photovoltaic string inverters. Electronics 2019, 8, 87. [CrossRef]

8. Norambuena, M.; Kouro, S.; Dieckerhoff, S.; Rodríguez, J. Reduced multilevel converter: A novel multilevel converter with a reduced number of active switches. IEEE Trans. Ind. Electron. 2017, 65, 3636-3645. [CrossRef]

9. Lakshmi, M.; Hemamalini, S. Nonisolated High Gain DC-DC converter for DC microgrids. IEEE Trans. Ind. Electron. 2017, 65, 1205-1212. [CrossRef]

10. Rodriguez, P.; Rouzbehi, K. Multi-terminal DC grids: Challenges and prospects. J. Mod. Power Syst. Clean Energy 2017, 5, 515-523. [CrossRef]

11. Kakigano, H.; Miura, Y.; Ise, T. Low-Voltage Bipolar-Type DC microgrid for super high quality distribution. IEEE Trans. Power Electron. 2010, 25, 3066-3075. [CrossRef]

12. Kim, J.-Y.; Kim, H.-S.; Baek, J.-W.; Jeong, D.-K. Analysis of effective three-level neutral point clamped converter system for the bipolar LVDC Distribution. Electronics 2019, 8, 691. [CrossRef] 
13. Aman, A.; Dwivedi, R.S.; Shah, J.D.; Singh, R.K.; Mahanty, R. Digitally controlled bipolar converter for DC micro grids. In Proceedings of the IECON 2017-43rd Annual Conference of the IEEE Industrial Electronics Society, Beijing, China, 29 December-1 November 2017; pp. 2258-2263.

14. Ferrera, M.B.; Litran, S.P.; Duran, E.; Enrique, J.M. New single-input, multiple-output converter topologies: Combining single-switch nonisolated DC-DC converters for single-input, multiple-output applications. IEEE Ind. Electron. Mag. 2016, 10, 6-20. [CrossRef]

15. Ferrera, M.B.; Litrán, S.P.; Durán, E.; Andújar, J.M. A converter for bipolar DC link based on SEPIC-Ćuk combination. IEEE Trans. Power Electron. 2015, 30, 6483-6487. [CrossRef]

16. Patra, P.; Patra, A.; Misra, N. A single-inductor multiple-output switcher with simultaneous buck, boost, and inverted outputs. IEEE Trans. Power Electron. 2011, 27, 1936-1951. [CrossRef]

17. Anand, A.; Singh, B.P. Power factor correction in Cuk-SEPIC-based dual-output-converter-fed SRM drive. IEEE Trans. Ind. Electron. 2017, 65, 1117-1127. [CrossRef]

18. Esram, T.; Chapman, P.L. Comparison of photovoltaic array maximum power point tracking techniques. IEEE Trans. Energy Convers. 2007, 22, 439-449. [CrossRef]

19. Raghavendra, K.V.G.; Zeb, K.; Muthusamy, A.; Krishna, T.N.V.; Kumar, S.V.S.V.P.; Kim, D.-H.; Kim, M.-S.; Cho, H.-G.; Kima, H.-J.; Raghavendra, K.V.G. A comprehensive review of DC-DC converter topologies and modulation strategies with recent advances in solar photovoltaic systems. Electronics 2019, 9, 31. [CrossRef]

20. Robles-Algarín, C.; Hernández, D.S.; Leal, D.R. A low-cost maximum power point tracking system based on neural network inverse model controller. Electronics 2018, 7, 4. [CrossRef]

21. Furtado, A.M.S.; Bradaschia, F.; Cavalcanti, M.C.; Limongi, L.R. A reduced voltage range global maximum power point tracking algorithm for photovoltaic systems under partial shading conditions. IEEE Trans. Ind. Electron. 2018, 65, 3252-3262. [CrossRef]

22. Zadeh, M.J.Z.; Fathi, S.; Jedari, M. A new approach for photovoltaic arrays modeling and maximum power point estimation in real operating conditions. IEEE Trans. Ind. Electron. 2017, 64, 9334-9343. [CrossRef]

23. Ramyar, A.; Iman-Eini, H.; Farhangi, S. Global maximum power point tracking method for photovoltaic arrays under partial shading conditions. IEEE Trans. Ind. Electron. 2016, 64, 2855-2864. [CrossRef]

24. Kumar, N.; Hussain, I.; Singh, B.P.; Panigrahi, B. Framework of maximum power extraction from solar PV panel using self predictive perturb and observe algorithm. IEEE Trans. Sustain. Energy 2017, 9, 895-903. [CrossRef]

25. Zhang, M.T.; Jiang, Y.; Lee, F.C.; Jovanović, M.M. Single-phase three-level boost power factor correction converter. In Proceedings of the 1995 IEEE Applied Power Electronics Conference and Exposition-APEC'95, Dallas, TX, USA, 5-9 March 1995; pp. 434-439.

26. Haddad, K. Three level DC-DC converters as efficient interface in two stage PV power systems. In Proceedings of the 2012 IEEE Energytech, Cleveland, OH, USA, 30-31 May 2012; pp. 1-6.

27. Lu, S.; Mu, M.; Jiao, Y.; Lee, F.C.; Zhao, Z. Coupled inductors in interleaved multiphase three-level DC-DC converter for high-power applications. IEEE Trans. Power Electron. 2015, 31, 120-134. [CrossRef]

28. Schoenbauer, S.; Martin-Lopez, F.R. Single Inductor Buck Boost Converter with Positive and Negative Outputs. U.S. Patent 2010,003,9080, 18 February 2010.

29. Duran-Gomez, J.; Garcia-Cervantes, E.; Lopez-Flores, D.; Enjeti, P.; Palma, L. Analysis and Evaluation of a Series-Combined Connected Boost and Buck-Boost DC-DC Converter for Photovoltaic Application. In Proceedings of the Twenty-First Annual IEEE Applied Power Electronics Conference and Exposition, APEC '06, Dallas, TX, USA, 19-23 March 2006; pp. 19-23.

30. Rezayi, S.; Iman-Eini, H.; Hamzeh, M.; Bacha, S.; Farzamkia, S. Dual-output DC/DC boost converter for bipolar DC microgrids. IET Renew. Power Gener. 2019, 13, 1402-1410. [CrossRef]

(C) 2020 by the authors. Licensee MDPI, Basel, Switzerland. This article is an open access article distributed under the terms and conditions of the Creative Commons Attribution (CC BY) license (http://creativecommons.org/licenses/by/4.0/). 